\title{
Periodontal Regeneration Using Gelatin Hydrogels Incorporating Basic Fibroblast Growth Factor
}

\author{
Toshiyuki Tamura ${ }^{1}$, Shigetoshi Yokoya ${ }^{2}$, Yohei Kamata ${ }^{2}$, Yukihiko Kinoshita ${ }^{3}$, Yasuhiko Tabata ${ }^{4}$ and \\ Goichi Matsumoto*3
}

${ }^{1}$ Department of Oral Interdisciplinary Medicine, Kanagawa Dental University, Japan

${ }^{2}$ Department of Highly Advanced Clinical Stomatology, Kanagawa Dental University, Japan

${ }^{3}$ Department of Oral and Maxillofacial Surgery, Kanazawa Medical University, Japan

${ }^{4}$ Department of Biomaterials, Field of Tissue Engineering, Japan

Received: April 23, 2018; Published: May 02, 2018

*Corresponding author: Goichi Matsumoto, Department of Oral and Maxillofacial Surgery, Kanazawa Medical University. 1-1 Daigaku, Uchinada, Kahoku-gunn, Ishikawa 920-0293, Japan

\begin{abstract}
We report here the clinical effects of the sustained release of basic fibroblast growth factor (bFGF) from gelatin hydrogel in cases of periodontal disease with infrabony defects. Patients with moderate to advanced periodontitis were treated with a mucoperiosteal flap operation. At the time of surgery, each bone defect was filled with gelatin hydrogel incorporating bFGF (bFGF/gelatin hydrogel). Probing pocket depth (PPD), clinical attachment level (CAL), and radiographic bone level were evaluated before treatment and at 3, 6, and 12 months after treatment. There were significant improvements in clinical parameters after treatment. There were no adverse effects during the treatment period. Topical application of bFGF/gelatin hydrogel may promote periodontal regeneration in cases of chronic periodontitis with infrabony defects.
\end{abstract}

Keywords: BFGF; Gelatin Hydrogel; DDS; Regeneration; Infrabony Defects; Periodontitis; Clinical Trial

\section{Introduction}

Recent progress in periodontal biology has demonstrated that undifferentiated mesenchymal stem cells and progenitor cells exist within the periodontal ligament [1,2] Therefore, enhancing the biological potential of these cells facilitates periodontal tissue regeneration. Bioactive factors that stimulate cellular proliferation and differentiation, such as bone morphogenetic protein-2 (BMP2), platelet-derived growth factor (PDGF), insulin-like growth factor (IGF), transforming growth factor beta (TGF- $\beta$ ), and basic fibroblast growth factor (bFGF), contribute to bone metabolism and to the organic inflammatory reaction, which is the healing process that takes place in wounds [3-5].

Many studies have shown that topically applying these bioactive factors to periodontal bone defects leads to regeneration of periodontal tissues [6-8]. We are particularly interested in bFGF, which has been shown to enhance the proliferation potency and chemotaxis of certain cells that originate in periodontal tissue and to enhance the healing of periodontal wounds [9-11]. Recent data gathered in a Phase II and III clinical trial regarding periodontal disease demonstrated that topical application of bFGF can successfully treat infrabony defects and class 2 furcation defects $[12,13]$. In this clinical experiment, hydroxypropyl cellulose was used as a vehicle to deliver bFGF in a controlled pattern of release. However, the half-life of the material proved to be short in the physiological environment. Therefore, a larger dosage is necessary for bFGF to be effective. In a search for materials that perform well, researchers have experimented with a variety of growth-factor delivery systems. They have incorporated growth factors into natural polymers, synthetic polymers, and ceramics, and they have experimented with physical entrapment, chemical immobilization, and other means to harness the growth factors into the delivery vehicles. Ikada et al. [14,15] have developed a drug delivery system (DDS) in which a growth factor that has been incorporated into gelatin hydrogel is released sustainably during the degradation of the gelatin hydrogel within the living body [16].

In their experiments with bone defects in animals, they found a significant increase in quantity of bone formed due to the bFGF- 
gelatin hydrogel $[17,18]$. In addition, Takayama et al. showed that topical application of bFGF/gelatin hydrogel considerably enhanced periodontal regeneration in a primate model [19]. We have sought to extend our knowledge of effective treatments of bone loss and periodontal disease with the case report presented here. Our goal is to further develop clinically effective methods of topically applying bFGF/gelatin hydrogel to treat chronic periodontitis accompanied by infrabony defects.

\section{Materials and Methods}

\section{Patients and study population}

For this clinical study, we recruited 23 patients (17 females and 6 males with a mean age of 50.3 years) who had moderate to advanced chronic periodontitis and who were scheduled to receive periodontal therapy at the Yokohama Clinic and Hospital of Kanagawa Dental University (Table 1). The study design and consent forms were approved by the ethics committee of Kanagawa Dental University. Criteria for enrollment in the study were:

a) a non-compromised systemic health condition and no contraindications for periodontal surgery;

b) a probing attachment loss equal to or greater than $4 \mathrm{~mm}$; and

c) Clinical and radiographic evidence of the presence of an interproximal defect with an infrabony component. All study subjects had destruction of periodontal tissue and at least one 1-, 2- or 3-walled bone defect. This clinical trial was conducted according to the schedule shown in Figure 1. Before periodontal surgical treatment, each patient received an initial preparatory session, including oral hygiene instruction, scaling, and root planing.

\begin{tabular}{lccccccc}
\hline \multicolumn{1}{c}{ Item } & $\begin{array}{c}\text { Before } \\
\text { registration }\end{array}$ & $\begin{array}{c}\text { Before } \\
\text { Operation }\end{array}$ & Operation & \multicolumn{2}{c}{$\begin{array}{c}\text { After operation } \\
\text { month }\end{array}$} \\
\hline Patient agreement & $\bullet$ & & & & & & \\
Registration & $\bullet$ & & & & & \\
Application of bFGF & & & $\bullet$ & & & \\
Radiography & & $\bullet$ & & $\bullet$ & $\bullet$ & $\bullet$ \\
Periodontal examination & & $\bullet$ & & $\bullet$ & $\bullet$ & $\bullet$ \\
\hline
\end{tabular}

Figure 1: Clinical trial schedule. The clinical trial was conducted in accordance with the clinical trial schedule.Periodontal examination consisted of measuring probing pocket depth and clinical attachment level.

\section{bFGF/gelatin hydrogel preparation}

The gelatin used in this study is an acid gelatin hydrogel that has an adjusted isoelectric point of 5.0 with moisture content of 95\%. It is of cow bone origin (Nitta Gelatin Co., Japan). The acid gelatin was freeze-dried, and a safety identification test and a sterility test were conducted. The bFGF used Fiblast Spray (Kaken Pharmaceutical Co., Japan) which is a human recombinant protein and pharmaceutical authorized as a therapeutic agent for pressure sores and skin ulcers. The bFGF/gelatin hydrogel material was prepared before surgery. A bFGF water solution consisting of 250 $\mu \mathrm{g}$ of bFGF dissolved in $300 \mu \mathrm{l}$ of purified water was prepared. The bFGF-water solution was applied to a freeze-dried gelatin sheet and adjusted to contain $100 \mu \mathrm{g}$ of bFGF for every $20 \mathrm{mg}$ of gelatin and was left standing afterwards for 24 hours at $4{ }^{\circ} \mathrm{C}$.

\section{Surgical procedures}

Following local anesthesia, intra-crevicular incisions were made extending to the neighboring teeth. Then, full-thickness mucoperiosteal flaps were raised vestibularly and orally. All granulation tissues were removed from defects and the roots were thoroughly scaled and planed by means of manual instruments. The defects and the adjacent mucoperiosteal flaps were then thoroughly rinsed with sterile saline, after which the defects werefilled with bFGF/gelatin hydrogel (Figure 2). After placing the hydrogel material, the flaps were repositioned and closed with sutures.

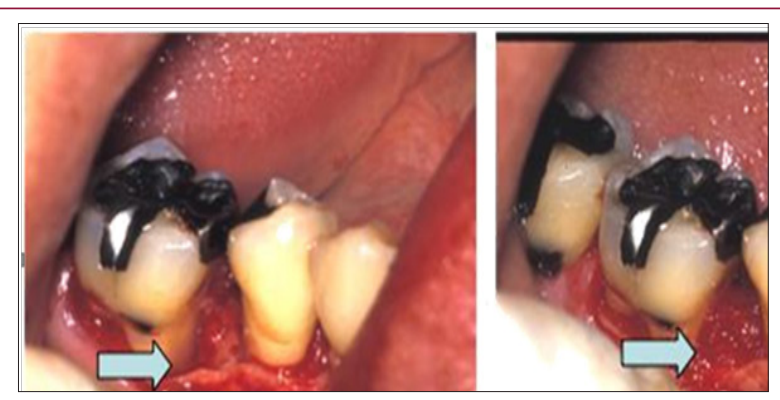

Figure 2: Application of bFGF/gelatin hydrogel to an infrabony defect. The mesial region of a mandibular rightfirst molar shows a 3-walled infrabony defect (arrow) (A). After granulation tissue was removed from the region, the defect was filled with bFGF/gelatin hydrogel (B).

\section{Postoperative care}

All patients received antibiotics orally for 5 days following surgery. The sutures were removed 7 to 14 days after surgery. Recall appointments were scheduled weekly during the first 4 weeks after surgery and then once a month for the rest of the 1-year observation period. Safety evaluations were conducted, subjective symptoms were recorded, and objective findings were confirmed by interview and visual inspection. 


\section{Outcomes}

The experimental outcomes of interest included soft-tissue and hard-tissue measurements of the intra-oral radiographs taken with a parallel technique:

a. Change in probing pocket depth (PPD)

b. Change in clinical attachment level (CAL)

c. Changes in the radiographic values of linear bone gain (LBG) and percentage of bone fill (BF)

The values of LBG and BF were determined by measuring intraoral radiographs in accordance with the methods of Nevins et al. [20]. LBG was determined by measuring the distance from the CE] to the base of the defect at the baseline minus the distance from the CEJ to the base of the defect at each of the post-surgical time points. The radiographic rate of bone fill was calculated by dividing the LBG by the depth of the original bone defect.

\section{Statistical analysis}

For statistical evaluation of the change from baseline to 3,6 , and 12 months, we used the Wilcoxson signed-rank test.

\section{Results}

Table 1: Characteristics of study subjects.

\begin{tabular}{|c|c|c|c|c|}
\hline Bone defect type & $\mathbf{n}$ & Female & Male & Mean age (years) \\
\hline 1-walled & 6 & 5 & 1 & 57.2 \\
\hline 2-walled & 10 & 7 & 3 & 54.9 \\
\hline 3-walled & 7 & 5 & 2 & 44.9 \\
\hline
\end{tabular}

Table 2: Periodontal examinations.

\begin{tabular}{|c|c|c|c|c|}
\hline & Before treatment & 3 months & 6 months & 12 months \\
\hline PPD $(\mathrm{mm})$ & $6.7 \pm 1.8$ & $3.2 \pm 1.3$ & $3.0 \pm 1.7$ & $3.8 \pm 1.9$ \\
\hline CAL $(\mathrm{mm})$ & $8.6 \pm 1.3$ & $6.3 \pm 1.4$ & $5.9 \pm 1.6$ & $5.9 \pm 2.0$ \\
\hline LBG $(\mathrm{mm})$ & $2.6 \pm 1.4$ & $1.6 \pm 0.8$ & $2.7 \pm 1.6$ & $3.5 \pm 2.1$ \\
\hline BF $(\%)$ & & $29.1 \pm 23.2$ & $50.7 \pm 21.7$ & $61.8 \pm 25.2$ \\
\hline
\end{tabular}

PPD: probing pocket depth, CAL: clinical attachment level, LBG: radiographic linear bone gain, $\mathrm{BF}$ : radiographic bone fill

The characteristics of the subjects in this study are shown in Table 1. The bFGF dose ranged from $40 \mu$ g to $185 \mu$ g (mean 89.7 $\mu \mathrm{g})$. All subjects completed the study; in all cases postoperative healing was uneventful. No allergic reactions, abscesses, infections, or other complications were observed during the study period. The pre-treatment and post-treatment clinical parameters are shown in Table 2. We compared the values of PPD, CAL, and LBG at 3,6 , and 12 months after treatment with the pre-treatment values. From before treatment to 12 months after treatment, the changes in mean PPD and mean CAL of treated sites were $3.8 \pm 1.9$ $\mathrm{mm}$ and $5.9 \pm 2.0 \mathrm{~mm}$, respectively. Also, at 12 months following treatment, hard tissue showed a mean LBG of $3.5 \pm 2.1 \mathrm{~mm}$ and a mean BF of $61.8 \pm 25.2 \%$. The mean depth of bone defects was less at both 6 months and 12 months compared with the pre-treatment mean (Figure 3). These differences were statistically significant. A representative case treated with $\mathrm{bFGF} /$ gelatin hydrogel is shown in Figure 2. In this case, the 12-month radiograph showed good bone fill compared with the pre-treatment radiograph (Figure 4).

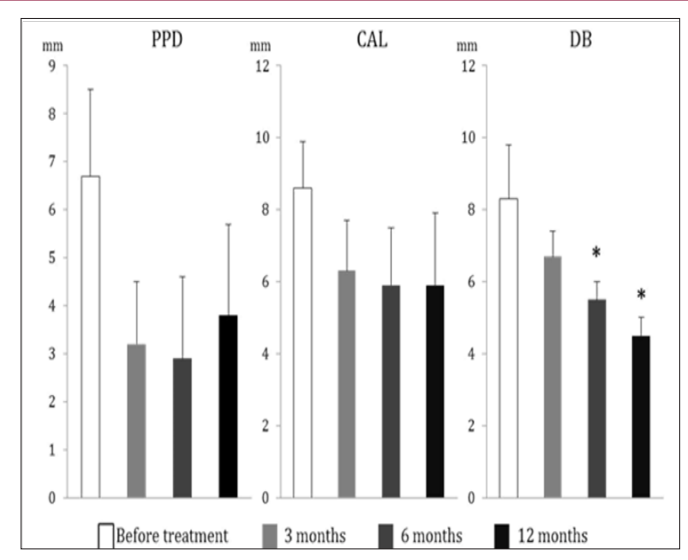

Figure 3: Changes of periodontal parameters. PPD: probing pocket depth, CAL: clinical attachment level, DB:depth of bone defect; *: significant difference from before treatment $(\mathrm{p}<0.05)$.

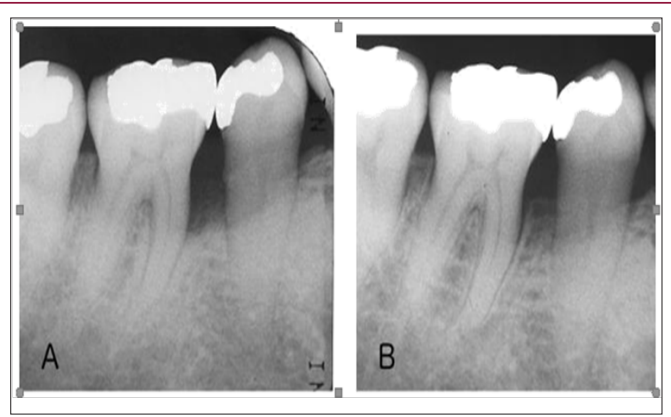

Figure 4: Dental radiographs. Preoperative radiograph of an infrabony defect on the mesial aspect of amandibular right first molar (A). At welve months after bFGF/gelatin hydrogel treatment (B). 


\section{Discussion}

Gelatin, a denatured collagen, is obtained by acid and alkaline processing of collagen isolated from bovine bone. This processing affects the electrical nature of collagen, yielding gelatin with different isoelectric points (IEPs) [15]. When mixed with positively or negatively charged gelatin, an oppositely charged protein ionically interacts to form a polyion complex. When bFGF that has been ionically complexed to an acidic gelatin hydrogel is placed in a target site, the bFGF will be released after a periodas a result of hydrogel degradation $[21,22]$. The degradation is controllable by changing the extent of cross-linking, which, in turn, affects the water content of the hydrogel. The rate of bFGF release accords well with the rate of hydrogel degradation.Gelatin hydrogel releases the protein drug without interfering with biological activity [16,22]. The optimum water content for promoting bone formation without disturbing it due to unabsorbed gelatin is $90-98 \%[23,24]$. In the present study, the water content of the hydrogel was $95 \%$. The bFGF release period associated with hydrogel degradation was expected to be about 4 weeks. We had no trouble placing bFGF/ gelatin hydrogel in the target site without it flowing out into the surrounding tissue.

Gelatin hydrogel has already been used to clinically deliver bFGF to treat ischemic limb disease and Bell's palsy $[25,26]$. The mechanisms by which bFGF facilitates periodontal regeneration are thought to include angiogenic activity and a mitogenic effect on mesenchymal stem cells within the periodontal ligament [3]. We hypothesize that periodontal regeneration is promoted by the sustained release of bFGF from gelatin hydrogel. In addition, we suspect that gelatin plays a role as a scaffold in the early stage of periodontal tissue regeneration.In our clinical study, a marked improvement of the infrabony defect was observed at 6 months after treatment. The radiographic and clinical parameters were stable at 12 months after bFGF/ gelatin hydrogel treatment. It has been reported that the clinical parameters and radiographic findings were stable at 6 years after $0.3 \%$ bFGF treatment. This may have a higher capacity for new alveolar bone regeneration than other periodontal regenerative therapies [27].

\section{Conclusion}

We evaluated the clinical effects of the sustained release of bFGF from gelatin hydrogel for the treatment of periodontal disease with infrabony defects. We treated 23 subjects with a mucoperiosteal flap operation. At the time of surgery, each bone defect was filled with $\mathrm{bFGF} /$ gelatin hydrogel, and this treatment led to improved clinical parameters, specifically, clinical attachment gain, probing depth reduction, and radiographic bone fill. We conclude by suggesting that the topical application of bFGF/gelatin hydrogel in the treatment of chronic periodontitis with infrabony defects or furcations is safe, leads to improvement of clinical parameters, and offers promise as a new avenue for periodontal regeneration. Since limited human clinical data are available, more studies with randomized control will be needed to fully evaluate the potential of bFGF/gelatin hydrogels for ehancing periodontal regeneration.

\section{References}

1 Cortellini P, Pini Prato G, Tonetti MS (1993) Periodontal regeneration of human infrabony defectsII Re-entry procedures and bone measures. J Periodontol 64(4): 261-268.

2 Torii D, Konishi K, Watanabe N, Goto S, Tsutsui T (2015) Cementogenic potential of multipotential mesenchymal stem cells purified from the human periodontal ligament. Odontology 103(1): 27-35.

3 Hughes FJ, Turner W, Belibasakis G, Martuscelli G (2006) Effects of growth factors and cytokines on osteoblast differentiation. Periodontol 2000(41): 48-72.

4 Giannobile WV, Somerman MJ (2003) Growth and amelogenin-like factors in periodontal wound healing: A systematic review. Ann Periodontol 8(1): 193-204.

5 Bateman J, Intini G, Margarone J, Goodloe S, Bush P, et al. (2005) Plateletderived growth factor enhancement of two alloplastic bone matrices. J Periodontol 76(11): 1833-1841.

6 Howell TH, Fiorellini JP, Paquette DW, Offenbacher S, Giannobile WV et al. (1997) A Phase I/II clinical trial to evaluate a combination of recombinant human platelet-derived growth factor-BB and recombinant human insulin-like growth factor-I in patients with periodontal disease. J Periodontol 68(12): 1186-1193.

7 Dereka XE, Markopoulou CE, Vrotsos IA (2006) Role of growth factors on periodontal repair. Growth Factors 24(4): 260-267.

8 Trombelli L, Farina R (2008) Clinical outcomes with bioactive agents alone or in combination with grafting or guided tissue regeneration. J ClinPeriodontol 35(8): 117-135.

9 Takayama S, Murakami S, Miki Y, Ikezawa K, Tasaka S, et al. (1997) Effects of basic fibroblast growth factor on human periodontal ligament cells. J Periodont Res 32(8): 667-675.

1010 Murakami S, Takayama S, Ikezawa K, Shimabukuro Y, Kitamura M, et al. (1999) Regeneration of periodontal tissues by fibroblast growth factor. J Periodontal Res 34(7): 425-430.

11 Rossa CJ, Marcantonio EJ, Cirelli JA, Marcantonio RA, Spolidorio LC, et al. (2000) Regeneration of class III furcation defects with basic fibroblast growth factor(b-FGF) associated with GTR: A descriptive and histometric study in dogs. J Periodontol 71(5): 775-784.

12 Kitamura M, Nakashima K, Kowashi Y, Fujii T, Shimauchi H, et al. (2008) Periodontal tissue regeneration using fibroblast growth factor-2: randomized controlled phase II clinical trial. PlosOne 3(7): e2611.

13 Kitamura M, Akamatsu M, Kawanami M, Furuichi Y, Fujii T, et al. (2016) Randomized Placebo-Controlled and Controlled Non-Inferiority Phase III Trials Comparing Trafermin, a Recombinant Human Fibroblast Growth Factor 2, and Enamel Matrix Derivative in Periodontal Regeneration in Intrabony Defects. J Bone Miner Res 31(4): 806-814.

14 Porter JR, Ruckh TT, Popat KC (2009) Bone tissue engineering: a review in bone biomimetics and drug delivery strategies. Biotechnol Prog 25(6): 1539-1560.

15 Mehta M, Schmidt Bleek K, Duda GN, Mooney DJ (2012) Biomaterial delivery of morphogens to mimic the natural healing cascade in bone. Adv Drug Deliv Rev 64(12): 1257-1276.

16 Ikada Y,Tabata Y (1998) Protein release from gelatin matrices. Adv Drug Deliv Rev 31(3): 287-301.

17 Tabata Y, Yamada K, Miyamoto S, Nagata I, Kikuchi H, et al. (1998) Bone regeneration by basic fibroblast growth factor complexed with biodegradable hydrogels. Biomaterials 19(7-9): 807-815.

18 Yamada K, Tabata Y, Yamamoto K, Miyamoto S, Nagata I, et al. (1997) Potential efficacy of basic fibroblast growth factor incorporated in biodegradable hydrogels for skull bone regeneration. J Neurosurg 86(5): 871-875. 
19 Takayama S, Murakami S, Shimabukuro S, Kitamura M, Okada H (2001) Periodontal regeneration by FGF-2 (bFGF) in primate models. J Dent Res 80(12): 2075-2079.

20 Nevins M, Giannobile WV, McGuire MK, Kao RT, Mellonig JT, et al. (2005) Platelet-derived growth factor stimulates bone fill and rate of attachment level gain: results of a large multicenter randomized controlled trial. J Periodontol 76(12): 2205-2215.

21 Tabata Y, Nagano A, Ikada Y (1999) Biodegradation of hydrogel carrier incorporatinfibloblast growth factor. Tissue Eng 5(2): 127-138.

22 Tabata Y, Hijikata S, Muniruzzaman M, Ikada Y (1999) Neovascularization effect of biodegradable gelatin microspheres incorporating basic fibroblast growth factor. J Biomater Sci Polym Ed 10(1): 79-94.

23 Yamada K, Tabata Y, Yamamoto K, Miyamoto S, Nagata I, et al. (1997) Potential efficacy of basic fibroblast growth factor incorporated in biodegradable hydrogels for skull bone regeneration. J Neurosurg 86(5): 871-875.

24 Kitamura M, Akamatsu M, Machigashira M, Hara Y, Sakagami R, et al. (2010) FGF-2 stimulates periodontal regeneration: results of a multicenter randomized clinical trial. J Dent Res 90(1): 35-40.

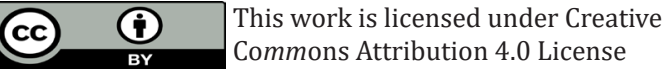

Submission Link: https://biomedres.us/submit-manuscript.php
25 Hato N, Nota J, Komobuchi H, Teraoka M, Yamada H, et al. (2011) Facial nerve decompression surgery using bFGF-impregnated biodegradable gelatin hydrogel in patients with Bell palsy. Otolaryngol Head Neck Surg 146(4): 641-646.

26 Marui A, Tabata Y, Kojima S, Yamamoto M, Tambara K, et al. (2007) A novel approach to therapeutic angiogenesis for patients with critical limb ischemia by sustained release of basic fibroblast growth factor using biodegradable gelatin hydrogel: an initial report of the phase I-IIa study. Circ J 71(8): 1181-1186.

27 Yoshinuma N, Koshi R, Kawamoto K, Idesawa M, Sugano N, et al. (2016) Periodontal regeneration with $0.3 \%$ basic fibroblast growth factor (FGF2) for a patient with aggressive periodontitis: a case report. J Oral Sci 58(1): 137-140.

$\begin{array}{ll}\text { BIOMEDICAL } & \text { Assets of Publishing with us } \\ \text { RESEARCHES } & \text { - Global archiving of articles } \\ & \text { - Immediate, unrestricted online access } \\ & \text { - Rigorous Peer Review Process } \\ & \text { - Authors Retain Copyrights } \\ \end{array}$

